\title{
Validation of the COPD Assessment Test in Patients with COPD in Iran
}

\section{Atefeh Fakharian, Shahram Kharabian Masouleh*, Saba Karimzadeh and Tayebeh Farhadi}

Chronic Respiratory Diseases Research Center (CRDRC), National Research Institute of Tuberculosis and Lung Diseases (NRITLD), Shahid Beheshti University of Medical Sciences, Tehran, Iran

${ }^{*}$ Corresponding author: Masouleh SK, Chronic Respiratory Diseases Research Center (CRDRC), National Research Institute of Tuberculosis and Lung Diseases (NRITLD), Shahid Beheshti University of Medical Sciences, Tehran, Iran, Tel: +982127122035; E-mail: drshahramkh@gmail.com

Rec date: May 22, 2017; Acc date: Jun 08, 2017; Pub date: Jun 15, 2017

Copyright: (C) 2017 Masouleh SK, et al. This is an open-access article distributed under the terms of the Creative Commons Attribution License, which permits unrestricted use, distribution, and reproduction in any medium, provided the original author and source are credited.

Citation: Fakharian A, Masouleh SK, Karimzadeh S, et al. (2017) Validation of the COPD assessment test in patients with COPD in Iran. Chron Obstruct Pulmon Dis 2: 22

\section{Abstract}

Background: Chronic obstructive pulmonary diseases (COPD) is among the most important causes of chronic disease in adulthood. COPD assessment test (CAT) and Saint George Respiratory Questionnaire (SGRQ) are two health related quality of life questioners validated for application in patients with COPD. Our purpose was to evaluate the validity and reliability of the short and easily translated CAT questionnaire for COPD patients.

Material and Methods: Between December 2015 and November 2016, in a cross-sectional pilot study, COPD patients attending Masih daneshvari hospital were asked to complete the Farsi translation of the CAT questionnaire. The inclusion criteria were patient consent, having stable COPD, ability to respond to questions and lack of other pulmonary disease. The results of the questionnaire were compared with the SGRQ and frequency of visits to the emergency room. The Cronbach's alpha coefficient was calculated for the questionnaire.

Result: 77 patients participated in this study with mean age of $63 \pm 12$ years (27-88). Sixty six subjects (85.7\%) were male and eleven (14.3\%) were female. Mean CAT score was $24 / 87 \pm 7$ (range 1-40). The Cronbach's alpha coefficient for the CAT questionnaire was calculated to be 0.732 . The correlation between CAT and SGRQ was significant ( $r=0.666$, $\mathrm{P}=0.000$ ). Correlation between CAT score and frequency of emergency visits and subjects' being married were $(r=0.627$, $\mathrm{P}=0.017)$ and $(\mathrm{r}=0.58, \mathrm{P}=0.024)$ respectively.

Conclusion: CAT questionnaire is well accepted by patients as is correlated well with SGRQ and patients' psychometric status. Trial registration number: IRCT2016102927929N3.

Keywords: Chronic obstructive pulmonary diseases; COPD assessment test; Validity; Reliability

\section{Introduction}

COPD is one of the most important causes of chronic diseases in adulthood [1] and a significant reason for disability and death in patients with moderate or severe airways obstruction [2]. Alongside some tests such as the spirometry and physical activity, influence of COPD on quality of life is measured via a number of questionnaires. The questionnaires have been developed to both assess severity of the disease at a point in time and evaluate effectiveness of treatments. In addition, although the degree of airway obstruction is a good measure for severity of COPD, it does not reflect and evaluate the effect of illness on the quality of life as well as does not have good correlation with the perception of disease symptoms in patients [1].

Qualitative studies on COPD patients, which consider the effects of their illness, are measured via frequency and severity of symptoms as well as physical and emotional wellbeing [3]. Hence, several questionnaires have been developed to evaluate effects of the illness on life. Well known questionnaires with acceptable validity and reliability include the CCQ (COPD Clinical Questionnaire), SGRQ (Saint George Respiratory Questionnaire), the CRQ (Chronic Respiratory Disease Questionnaire) and CAT (COPD Assessment Test) questionnaires. CCQ, SGRQ and CRQ are longer than CAT and have more involved scoring methods $[4,5]$.

Quality of life questionnaires can be disease specific or generic to apply for any illness. A well-known example of the generic questionnaires is SF-36 (short form). SF-36 is used to evaluate quality of life in patients with chronic pulmonary disease such as COPD and assess the effectiveness of treatments [6]. SF-36 is a self-reported questionnaire and has been translated in many languages.

Overall, the impression of patients and their physician has been utilized to develop of a questionnaire [7]. It is also shown that literacy is important for being able to respond to quality of life questionnaires [8]. Some qualities such as comprehensiveness, shortness, cultural adaptability and expression in simple language are significant for selection of a questionnaire. Recently, the CAT questionnaire has been developed based on working with patients and for becoming familiar with their problems in their own language [9]. In some studies, in order to evaluate clinically outcome measures of patients having COPD, CAT questionnaire was compared with 
the HRQL (Health Related Quality of Life) as well as the CRQ questionnaires, separately $[10,11]$.

The aim of this study was validation of a short and easily translated CAT questionnaire in patients with COPD in Masih daneshvari hospital, Tehran, Iran. The results of this study may be used to evaluate quality of life as well as effectiveness of treatment modalities such as rehabilitation in the future.

\section{Materials and Methods}

The current research was a cross-sectional pilot study. Persian translation of the CAT questionnaire was completed by COPD patients attending Masih Daneshvari Hospital during the time period between December 2015 and November 2016. The diagnosis of COPD was confirmed by using the patients' medical history, physical examination and irreversible PFT obstructive pattern. All patients attending either the emergency department or general medical ward who met the inclusion criteria were entered into the study. A series of the patients were on optimal therapy and some patients were any outpatients. The inclusion criteria included patient consent, having stable COPD, ability to respond to questions and lack of other pulmonary disease. For patients who were illiterate, the questionnaire was read by interviewers.

The CAT questionnaire has been developed to evaluate quality of life and effect of illness on patients with COPD in their own language. It has eight questions and is short. Each question has a possible score of 0-5 with a questionnaire total score of 40 . This questionnaire had been translated by the Breslin method to the Farsi language (questions were translated, reverse translated, and have been culturally adapted by specialists in the field). The SGRQ is specific for chronic pulmonary disease patients and is self-reported by the patients. It takes close to 10 minutes to complete the questionnaire. It has 50 questions in three subsections: symptoms, activities and impact. The questions have 0-100 points and are expressed in percentages. The higher the score, the worse the quality of life is. The SGRQ has been translated to the Persian language and has acceptable validity and reliability [7].

In this study, the result of CAT questionnaire was compared with the SGRQ as well as the frequency of visits to the emergency room, separately. The mentioned information and patient's demographic data were saved and analyzed using SPSS 16 statistical software.

The Cronbach's alpha coefficient was calculated for the questionnaire. The Chi-square test was used for evaluating relatedness of questionnaire results with other tests such as other measures of severity of illness and influence of demographic characteristics.

\section{Results}

In total, 77 patients participated in this study with mean age of $63 \pm 12$ years (27-88). Sixty six subjects $(85.7 \%)$ were male and 11 subjects (14.3\%) were female. Patient's information is summarized in Table 1. Mean CAT score was $24.87 \pm 7$ (range 1-40). The Cronbach's alpha coefficient was calculated to be 0.732 for the CAT questionnaire. There was statistically significant correlation between the scores from the CAT questionnaire and the total scores from the SGRQ ( $r=0.666$, $\mathrm{P}=0.000)$.

Table 1: Patient information.

\begin{tabular}{|c|c|}
\hline Characteristic & Value and Percentages \\
\hline Age & $63 \pm 12$ years $(27-88)$ \\
\hline \multicolumn{2}{|l|}{ Gender } \\
\hline Male & $66(85 / 7 \%)$ \\
\hline Female & $11(14 / 3 \%)$ \\
\hline \multicolumn{2}{|l|}{ Education } \\
\hline Illiterate & $25(32 \%)$ \\
\hline Primary school & $33(43 \%)$ \\
\hline Junior High & $5(7 \%)$ \\
\hline High school & $9(11 \%)$ \\
\hline University & $5(7 \%)$ \\
\hline \multicolumn{2}{|l|}{ Occupation } \\
\hline Laborer & $11(15 \%)$ \\
\hline Homemaker & $9(11 \%)$ \\
\hline Self-employed & $40(52 \%)$ \\
\hline Retired & $11(15 \%)$ \\
\hline Doctor & $3(4 \%)$ \\
\hline Unemployed & $3(4 \%)$ \\
\hline \multicolumn{2}{|l|}{ Marital status } \\
\hline Single & $74(96 \%)$ \\
\hline Married & $3(4 \%)$ \\
\hline \multicolumn{2}{|l|}{ Smoking } \\
\hline No & $62(80 \%)$ \\
\hline Yes & $15(20 \%)$ \\
\hline \multicolumn{2}{|l|}{ Use of opium } \\
\hline No & $49(63 \%)$ \\
\hline Yes & $28(37 \%)$ \\
\hline
\end{tabular}

Regression analysis showed that there is statistically significant correlation between frequency of visit to the emergency room with the CAT questionnaire score. Correlation between the score of the CAT questionnaire and frequency of emergency visits in the past three months had a standard coefficient of 0.627 with $\mathrm{P}=0.017$. Regression analysis also showed that there is statistically significant correlation between 
marital status with the CAT questionnaire score. Correlation between the score of the CAT questionnaire and being married had a standard coefficient of 0.580 with $P=0.024$. The correlation between CAT score and SGRQ, CAT score and frequency of emergency visit as well as CAT score and marital status is summarized in Table 2.

Table 2: Correlation between CAT questionnaire and SGRQ, frequency of emergency visit and marital status.

\begin{tabular}{|l|l|l|l|}
\hline \multicolumn{1}{|c|}{ Value } & SGRQ & $\begin{array}{l}\text { Frequency of emergency } \\
\text { visits }\end{array}$ & $\begin{array}{l}\text { Marital } \\
\text { status }\end{array}$ \\
\hline $\begin{array}{l}\text { CAT } \\
\text { value })\end{array}$ & $0.000^{\star \star}$ & $0.017^{\star}$ & $0.024^{\star}$ \\
\hline CAT $(r)$ & 0.666 & 0.627 & 0.58 \\
\hline
\end{tabular}

\section{Discussion}

In order to evaluate the quality of life and achieve a better relation between the COPD patients and physician, Jones et al. developed SGRQ. The questionnaire was developed using patients descriptions of the effects of the illness symptoms on their overall health status. The questionnaire's translation in various countries has been very easy $[12,13]$. In Europe and the United States, a version of this questionnaire containing 21 question has been used in large studies $(n=1503)$ [14]. The Cronbach's alpha coefficient for internal reliability has been 0.88 . The questionnaires repeatability has also been very good with intra class correlation coefficient of 0.8 .

However to select a questionnaire, some items such as comprehensiveness, shortness, cultural adaptability and expression in simple language are important [9]. In this pilot study, a short and easily translated CAT questionnaire was validated in COPD patients in Iran. The Cronbach's alpha coefficient for the CAT questionnaire was 0.732 . The Cronbach's alpha coefficient was employed to check the internal reliability of the questionnaire. Results of the Regression analysis showed that there was statistically significant correlation between the CAT score and the total SGRQ score. There was also statistically significant correlation between frequency of emergency visits and CAT score. Furthermore, there was statistically significant correlation between being married and CAT score.

In a study in the United States $(n=53)$, correlation coefficient of an eight question version of CAT with the SGRQ was found to be $r=0.8$ [14]. The score difference for patients in the controlled state and during exacerbation has been five points out of the total of $40(12 \%, P<0.0001)$. In a review study, quality of life questionnaires for COPD patients were evaluated and symptoms such as pain, interest in life and emotional activities were addressed in disease specific questionnaires [15]. In eight studies that were done in private offices, the CAT questionnaire was evaluated with participation of pulmonary rehabilitation patients. Results of these studies indicated that there is strong evidence for the questionaries' content validity, internal consistency and correlation with similar instruments. In another study in Netherlands, the CAT, CCQ and SGRQ were completed by 90 COPD patients in stage I-IV during three visits and compared with each other [16]. This study showed that the CAT and CCQ both had acceptable validity, reliability and repeatability. The Chronbach's alpha coefficients for the CAT and CCQ were 0.86 and 0.89 , respectively. Scores from two questionnaires had good correlation with each other. Comparing CCQ and CAT questionnaires, $61.1 \%$ of the patients believed that the CCQ expresses their situation better and contains more details about their pulmonary problems which are more important to them than sleep and energy levels.

As far as we know, a short and easily translated CAT questionnaire was validated in COPD patients in Iran for the first time in this study. The CAT questionnaire has been translated to other languages including Japanese where it has had a Chroncach's alpha coefficient of 0.891 and shown high correlation with scores from the SGRQ [17]. This questionnaire was also translated to Chinese and Turkish and had acceptable report $[18,19]$. The CAT questionnaire has been used to follow the condition of patients with COPD, particularly for evaluating health improvement with rehabilitation and recovery from disease exacerbation [20-22]. Development of the CAT questionnaire to become familiar with patients problems in their own language has some advantages including its well acceptance by patients and correlation with SGRQ and patients' psychometric status [23].

\section{Conclusion}

In this pilot study, the CAT questionnaire was well accepted by patients and most questionnaires were fully completed. The Cronbach's alpha coefficient result showed that the CAT questionnaire had acceptable reliability. The validity of the questionnaire was supported by correlation with the scores from the SGRQ. This study was a pilot study performed with participation of patients at our hospital. A bigger study including patients in the controlled state and in different stages of the illness can be more comprehensive.

\section{Acknowledgement}

Authors would like to thank all colleagues at Masih Daneshvari Hospital that helped with preparation of this manuscript.

\section{References}

1. Miravitlles M, Vogelmeier C, Roche N, Halpin D, Cardoso J, et al. (2016) A review of national guidelines for management of COPD in Europe. Eur Respir J 47: 625-637.

2. Miravitlles M, Soriano JB, Garcia-Rio F, Muñoz L, Duran-Tauleria E, et al. (2009) Prevalence of copd in spain: Impact of undiagnosed copd on quality of life and daily life activities. Thorax 64: 863-868.

3. Vestbo J, Hurd SS, Agustí AG, Jones PW, Vogelmeier C, et al. (2013) Global strategy for the diagnosis, management, and prevention of chronic obstructive pulmonary disease: GOLD executive summary. American journal of respiratory and critical care medicine 187 : 347-365.

4. Jones PW, Price D, van der Molen T (2011) Role of clinical questionnaires in optimizing everyday care of chronic obstructive pulmonary disease. In J Chron Obstruct Pulmonary Dis 6: 289-296. 
5. Jones P, Higenbottam $T$ (2007) Quantifying of severity of exacerbations in chronic obstructive pulmonary disease: adaptations to the definition to allow quantification. Proc Am Thorac Soci 4: 597-601.

6. Mahler DA, Mackowiak JI (1995) Evaluation of the short-form 36item questionnaire to measure health-related quality of life in patients with COPD. Chest 107: 1585-1589.

7. Wyrwich KW, Tierney WM, Babu AN, Kroenke K, Wolinsky FD (2005) A Comparison of Clinically Important Differences in HealthRelated Quality of Life for Patients with Chronic Lung Disease, Asthma, or Heart Disease. Health Serv Research 40: 577-592.

8. Scott AS, Baltzan MA, Dajczman E, Wolkove N (2011) Patient knowledge in chronic obstructive pulmonary disease: Back to basics. J Chron Obstruc Pulmo Dis 8: 375-379.

9. Jones P, Harding G, Berry P, Wiklund I, Chen WH, et al. (2009) Development and first validation of the COPD Assessment Test. Eur Respir J 34: 648-654.

10. Harper R, Brazier JE, Waterhouse JC, Walters SJ, Jones NM, et al. (1997) Comparison of outcome measures for patients with chronic obstructive pulmonary disease (COPD) in an outpatient setting. Thorax 52: 879-887.

11. Glaab T, Vogelmeier C, Buhl R (2010) Outcome measures in chronic obstructive pulmonary disease (COPD): Strengths and limitations. Respiratory Res 11: 79.

12. Jones PW, Quirk FH, Baveystock CM (1991) The St George's Respiratory Questionnaire. Respir Med 85: 25-31.

13. Jones PW, Quirk FH, Baveystock CM, Littlejohns P (1992) A selfcomplete measure of health status for chronic airflow limitation. The St. George's Respiratory Questionnaire. Am Rev Resp Dis 145: 1321-1327.

14. Ferrer M, Villasante C, Alonso J, Sobradillo V, Gabriel R, et al. (2002) Interpretation of quality of life scores from the St George's Respiratory Questionnaire. Eur Respir J 19: 405-413.
15. Weldam SW, Schuurmans MJ, Liu R, Lammers JW (2013) Evaluation of Quality of Life instruments for use in COPD care and research: A systematic review. Int Journal Nurs Stud 50: 688-707.

16. Tsiligianni IG, van der Molen T, Moraitaki D, Lopez I, Kocks JW, et al. (2012) Assessing health status in COPD. A head-to-head comparison between the COPD assessment test (CAT) and the clinical COPD questionnaire (CCQ). BMC Pulmonary Med 12: 1.

17. Tsuda T, Suematsu R, Kamohara K, Kurose M, Arakawa I, et al. (2012) Development of the Japanese version of the COPD Assessment Test. Respir Investig 50: 34-39.

18. Chai J, Liu T, Cai B (2011) Evaluation of clinical significance of chronic obstructive pulmonary disease assessment test. Chin J Tuberculosis Respiratory Diseases 34: 256-258.

19. Yorgancıoğlu A, Polatı $M$, Aydemir Ö, Yılmaz DN, Kırkıl G, et al. (2011) Reliability and validity of Turkish version of COPD assessment test. Tuber Toraks 60: 314-320.

20. Ringbaek T, Martinez G, Lange $P$ (2012) A comparison of the assessment of quality of life with CAT, CCQ, and SGRQ in COPD patients participating in pulmonary rehabilitation. J Chron Obstr Pulmo Dis 9: 12-15.

21. Jones PW, Harding G, Wiklund I, Berry P, Tabberer M, et al. (2012) Tests of the responsiveness of the COPD assessment test following acute exacerbation and pulmonary rehabilitation. Chest J 142: 134-140.

22. Agustí A, Soler JJ, Molina J, Muñoz MJ, García-Losa M, et al. (2012) Is the CAT questionnaire sensitive to changes in health status in patients with severe COPD exacerbations?. J Chr Obstr Pulmo Dis 9: 492-498.

23. Fakharian A, Talischi F, Tafti SF (2015) Evaluation of the validity and reliability of the CAT (COPD assessment test) questionnaire among COPD patients attending Masih Daneshvari Hospital. Eur Respir J 46. 